\title{
Toxicities of Cadmium, Copper, and Zine to Four Juvenile Stages of Chinook Salmon and Steelhead
}

\author{
Gary A. Chapman \\ Corvallis Environmental Research Laboratory, Western Fish Toxicology Station \\ U.S. Environmental Protection Agency, Corvallis, Oregon 97330
}

\begin{abstract}
Continuous-flow toxicity tests were conducted to determine the relative tolerances of newly hatched alevins, swim-up alevins, parr, and smolts of chinook salmon (Oncorhynchus tshawytscha) and steelhead (Salmo gairdneri) to cadmium, copper, and zinc. Newly hatched alevins were much more tolerant to cadmium and, to a lesser extent, to zinc than were later juvenile forms. However, the later progression from swim-up alevin, through parr, to smolt was accompanied by a slight increase in metal tolerance. The 96-h LC50 values for all four life stages ranged from 1.0 to $>27$ $\mu \mathrm{g} \mathrm{Cd} /$ liter, 17 to $38 \mu \mathrm{g} \mathrm{Cu} /$ liter, and 93 to $815 \mu \mathrm{g} \mathrm{Zn/liter.} \mathrm{Steelhead} \mathrm{were} \mathrm{consistently} \mathrm{more}$ sensitive to these metals than were chinook salmon. When a sensitive life stage for acute toxicity tests with metals is sought, the more resistant newly hatched alevins should be avoided. Although tolerance may increase with age, all later juvenile life stages are more sensitive and should give similar results.
\end{abstract}

Juvenile anadromous salmonids reside in fresh water for up to 2 yr prior to their migration to the sea, and during their freshwater residency pass through several physiologically and morphologically distinct stages. The relative resistance of each of these stages to any potential pollutant is an important consideration in evaluation and application of toxicity data. Most acute toxicity tests with salmonids are conducted on parr stage juveniles, primarily because of their general availability and convenient size. Only a few acute toxicity tests have been reported with embryos, alevins, or smolts, although chronic tests usually include most of these stages.

This study was conducted to determine the relative toxicities of cadmium, copper, and zinc to various juvenile stages of chinook salmon (Oncorhynchus tshawytscha) and steelhead (Salmo gairdneri).

\section{METHODS}

There is no standard terminology for the various salmonid life stages, although several have been proposed (Hubbs 1943; Balon 1975; Snyder 1976). The life stage terminology used here is essentially that used by Norman (1947). The life stages that were compared in the following series of toxicity tests were newly hatched alevins, swim-up alevins, 5- to 8-mo-old parr, and smolts. For brevity these life stages will be identified as alevins, swim-ups, parr, and smolts, respectively.

Eyed eggs of chinook salmon and steelhead were obtained from hatcheries of the Oregon Fish Commission and the Oregon State Wildlife Commission. All eggs were dipped 5 to $15 \mathrm{~min}$ in disinfectant solutions (Wescodyne or Betadyne) ${ }^{1}$ of 1:150 to $1: 600$ dilution, adjusted to $\mathrm{pH} 7$, prior to being brought into the laboratory. Eggs and alevins were held in vertical-flow incubators; when the alevins reached the swim-up stage they were transferred to troughs and subsequently to larger tanks. All swim-up and older fish were fed commercial salmon or trout food (usually Oregon Moist), but the test fish were not fed for $48 \mathrm{~h}$ prior to or during tests, nor for $48 \mathrm{~h}$ prior to any handling of the fish.

The laboratory water was supplied by wells on the banks of the nearby Willamette River. Except for lower concentrations of suspended solids, organic carbon, iron, and manganese, the well water quality was usually similar to that of the river (Table 1). Increases of two- to fivefold in well-water dissolved solids, alkalinity, and hardness occur sporadically during winter months (Samuelson 1976). Whenever these peaks occurred, normal water quality was main-

\footnotetext{
${ }^{1}$ Mention of product does not constitute endorsement by the U.S. Environmental Protection Agency.
} 
TABLE 1.-Mean water quality characteristics (mg/liter) of Willamette River water and well water, based on weekly samples analyzed at the Environmental Research Laboratory, Corvallis.

\begin{tabular}{|c|c|c|c|c|}
\hline $\begin{array}{c}\text { Water quality } \\
\text { character }\end{array}$ & $\begin{array}{c}\text { Willamette } \\
\text { River }\end{array}$ & WFTS wella & WFTS wellb & $\begin{array}{l}\text { Blend: WFTS well } \\
\text { + R.O. Product }\end{array}$ \\
\hline Alkalinity & 23 & 24 & 63 & 22 \\
\hline Ammonia & 0.06 & 0.04 & 0.06 & 0.02 \\
\hline Cadmium & $<0.001$ & $<0.001$ & $<0.001$ & $<0.001$ \\
\hline Calcium & 5.5 & 6.8 & 21.3 & 6.1 \\
\hline Chloride & 4 & 6 & 11.3 & 6 \\
\hline Chromium & $<0.002$ & $<0.002$ & $<0.001$ & $<0.002$ \\
\hline Cobalt & $<0.001$ & $<0.002$ & 0.002 & $<0.001$ \\
\hline Copper & 0.003 & 0.003 & 0.003 & 0.002 \\
\hline Dissolved solids & 52 & 59 & 130 & 53 \\
\hline Hardness & 22 & 25 & 67 & 24 \\
\hline Iron & 0.736 & 0.098 & 0.050 & 0.036 \\
\hline Lead & 0.003 & 0.004 & 0.003 & 0.006 \\
\hline Magnesium & 2.1 & 1.8 & 4.8 & 1.8 \\
\hline Manganese & 0.031 & 0.004 & 0.002 & 0.002 \\
\hline Mercury & 0.001 & 0.001 & $<0.001$ & 0.001 \\
\hline Nickle & 0.002 & 0.002 & 0.002 & 0.002 \\
\hline Nitrate & 0.150 & 0.190 & 0.578 & 0.180 \\
\hline Organic carbon & 3.4 & 1.3 & No data & 1.4 \\
\hline Potassium & 0.08 & 0.6 & 0.8 & 0.4 \\
\hline Sodium & 4.1 & 5.0 & 7.0 & 4.4 \\
\hline Sulfate & 6.6 & 4.2 & 17.3 & 5.8 \\
\hline Suspended solids & 15 & 1.5 & 1.3 & $<1.0$ \\
\hline Zinc & 0.009 & 0.005 & 0.005 & 0.004 \\
\hline
\end{tabular}

Values exclude winter periods of higher hardness and alkalinity.

b Values during winter periods of higher hardness and alkalinity.

c R.O. = reverse osmosis.

tained in the test aquaria by mixing ambient well water with the appropriate amount of reverse osmosis-treated well water. Uniform water quality was necessary since significant variation would affect metal toxicity and negate comparisons among tests conducted in waters of significantly differing quality.

Water for all tests was pretreated by ultraviolet sterilization, aerated by jetting and spraying, and maintained at a constant temperature. Nominal water temperature for all tests was $12 \mathrm{C}$ and fish were held within $\pm 2 \mathrm{C}$ of this temperature for at least $3 \mathrm{wk}$ before transfer to test aquaria.

Smolt tests were conducted in 100-liter glass aquaria with a water volume of about 70 liters. All other tests were conducted in 19-liter glass aquaria with a water volume of about 14 liters. All aquaria were dosed by diluters; the larger aquaria were served by serial diluters, similar to that described by Warner (1964), which delivered 3 liters/min/ concentration. The smaller aquaria were supplied by 2 liters/concentration/cycle proportional diluters similar to that described by Mount and Brungs (1967). Each diluter provided six metal concentrations, including the control, and the flow for each concentration was split equally between duplicate aquaria. Fifty percent replacement times for the large and small aquaria were $32 \mathrm{~min}$ and $20 \mathrm{~min}$, respectively, as calculated from Sprague (1969).

Each test system was shrouded to control light and minimize disturbance. Photoperiod was adjusted semimonthly to correspond with the existing local day length. In some toxicity tests, $30 \mathrm{~min}$ dawn and dusk twilight periods were provided by two 20 -watt incandescent lamps powered through a motor-driven rheostat. In other toxicity tests dim twilight illumination was maintained throughout the test to facilitate mortality checks during the night. In both cases, daytime illumination was supplied by two 40watt fluorescent tubes, and light intensity at the water surface was about 500 lux.

Prior to each test, equal numbers of fish were distributed among 37 groups, the 36 test aquaria and a single length-weight sample, in a stratified random manner. After being placed in the aquaria, all fish except alevins were allowed 1 wk under control 
TABLE 2.-Fish number and fish size data for each set of toxicity tests with the indicated species and stage.

\begin{tabular}{|c|c|c|c|c|c|c|c|c|c|c|}
\hline \multirow[b]{2}{*}{ Species } & \multirow[b]{2}{*}{ Stage } & \multirow[b]{2}{*}{$N^{\mathrm{a}}$} & \multicolumn{2}{|c|}{$\begin{array}{l}\text { Wet weight } \\
\text { (g) }\end{array}$} & \multicolumn{2}{|c|}{$\begin{array}{c}\text { Fork length } \\
(\mathrm{cm})\end{array}$} & \multicolumn{2}{|c|}{$\begin{array}{c}\text { Condition } \\
\text { factor }^{b}\end{array}$} & \multicolumn{2}{|c|}{$\begin{array}{l}\text { Developmental } \\
\text { index }\end{array}$} \\
\hline & & & mean & SD & mean & SD & mean & $\mathrm{SD}$ & mean & SD \\
\hline Steelhead & Alevin $^{\mathrm{d}}$ & 20 & & & & & & & & \\
\hline Steelhead & Swim-up de & 20 & 0.17 & 0.02 & & & & & 0.93 & 0.03 \\
\hline Steelhead & Parr ${ }^{I}$ & 20 & 6.96 & 2.27 & 8.6 & 0.9 & 1.06 & 0.06 & & \\
\hline Steelhead & Smolt ${ }^{f}$ & 10 & 68.19 & 15.52 & 18.8 & 1.5 & 1.01 & 0.07 & & \\
\hline Chinook salmon & Alevin $^{\text {ef }}$ & 20 & 0.05 & 0.01 & & & & & 0.19 & 0.03 \\
\hline Chinook salmon & Swim-up ${ }^{\text {ef }}$ & 20 & 0.23 & 0.01 & & & & & 0.68 & 0.06 \\
\hline Chinook salmon & Parr ${ }^{d}$ & 20 & 11.58 & 3.91 & 9.6 & 1.1 & 1.27 & 0.06 & & \\
\hline Chinook salmon & Smolt ${ }^{p}$ & 10 & 32.46 & 25.34 & 14.4 & 3.3 & 0.94 & 0.10 & & \\
\hline
\end{tabular}

a Number of fish per aquarium and in the length-weight sample.

beight $\times 100 /$ length ${ }^{3}$.

c Fish weight without yolk/fish weight including yolk.

d Test conducted in well water:reverse osnosis blend.

e Weight without yolk.

' Light:dark photoperiod.

conditions to acclimate and recover from handling before the toxicity tests were begun. Tests with alevins were started the same day fish were placed into the aquaria. Fish in the length-weight sample were immediately killed in a strong solution of anesthetic (ethyl m-aminobenzoate methanesulfonate), blotted, measured, and weighed. Alevins and swim-up alevins were weighed, their yolks were excised, and the fish were reweighed. Length, weight, and related data are summarized in Table 2.

Twenty fish per duplicate aquarium was the stocking density for all tests with alevins, swim-ups, and parr. Ten fish per aquarium was the stocking density for the smolt tests. Smolt tests were conducted concurrently on both species in common aquaria, although only one set of duplicate aquaria received steelhead smolts. Toxicity tests with cadmium, copper, and zine were conducted concurrently for each life stage.

Loading factors ranged from 0.2 to 14.4 $\mathrm{g} /$ liter of aquarium volume and from 0.01 to $0.47 \mathrm{~g} /$ liter/day based on flow rates. These loading factors were within recommended limits for flow-through toxicity tests (Committee on Methods for Toxicity Tests with Aquatic Organisms 1975).

Tests were started by allowing the metal concentrations in the aquaria to increase at the rates determined by the volume replacement times; nominal concentrations were approached in about $2 \mathrm{~h}$. Checks for dead fish were made three times per day for the first $96 \mathrm{~h}$ and at least daily thereafter; dead fish were removed when observed. Absence of ventilation, loss of irritability, and absence of muscular tremors were criteria of death.

Calculations of LC10 and LC50 values (concentrations killing $10 \%$ and $50 \%$ of the test fish, respectively) were made for 96and 200-h exposure periods and at the termination of each test $(186-390 \mathrm{~h})$. All LC10 and LC50 values were obtained from a computer program which linearly regressed percent mortalities (expressed as logits) against the $\log s$ of the mean metal concentration.

Samples for the determination of metal concentrations were taken daily from at least one aquarium containing each metal concentration. Samples for heavy metal analysis were taken in acid-washed, sample-rinsed containers, and the samples were routinely acidified by the addition of one volume percent of concentrated nitric acid. Metal levels were measured by atomic absorption spectrophotometry; flame was used for zinc and graphite furnace for cadmium and copper. Except for cadmium concentrations greater than $6 \mu \mathrm{g} / \mathrm{liter}$, absorption was linear within the working range. Analytical precision was $\pm 3 \mu \mathrm{g} /$ liter for zinc, $\pm 0.5 \mu \mathrm{g} /$ liter for copper, $\pm 0.1 \mu \mathrm{g} /$ liter for cadmium concentrations below $6 \mu \mathrm{g} /$ liter, and \pm 0.4 $\mu \mathrm{g} /$ liter for cadmium concentrations between 6 and $40 \mu \mathrm{g} /$ liter. In addition, diluter function, diluter cycle count, and stock solution use rate were checked daily. Stock solutions were prepared from reagent grade chloride salts of the metals and were acidi- 
TABLE 3.-Calculated 96- $h$ and 200-h LC50 values, 200-h LC10 values, and in parentheses, $95 \%$ confudence limits ( $\mu g / l i t e r)$, for various stages of steelhead and chinook salmon exposed to cadmium, copper, or zinc.

\begin{tabular}{|c|c|c|c|c|c|c|c|c|}
\hline \multirow{2}{*}{$\begin{array}{l}\text { Metal } \\
\text { and LC }\end{array}$} & \multicolumn{4}{|c|}{ Steelhead } & \multicolumn{4}{|c|}{ Chinook salmon } \\
\hline & Alevin & Swim-up & Parr & Smolt & Alevin & Swim-up & Parr & Smolt \\
\hline \multicolumn{9}{|l|}{ Cadmium } \\
\hline $\begin{array}{r}\text { 96-h LC50 } \\
200-h \text { LC50 } \\
200-h \text { LC10 }\end{array}$ & $\begin{array}{l}>27 \\
>27^{a} \\
>6^{a}\end{array}$ & $\begin{array}{l}1.3(1.2-1.4) \\
1.3(1.2-1.4) \\
1.0(0.9-1.1)\end{array}$ & $\begin{array}{l}1.0(0.8-1.1) \\
0.9(0.8-1.0) \\
0.7(0.6-0.8)\end{array}$ & $\begin{array}{c}>2.9(>2.3) \\
1.6(\mathrm{al} \text { values }) \\
0.8(<1.3)\end{array}$ & $\begin{array}{l}>26 \\
>26 \\
18-26\end{array}$ & $\begin{array}{l}1.8(1.7-2.0) \\
1.6(1.4-1.9) \\
1.2(0.9-1.4)\end{array}$ & $\begin{array}{l}3.5(2.8-5.6) \\
2.0(1.8-2.2) \\
1.3(1.0-1.5)\end{array}$ & $\begin{array}{c}>2.9 \\
2.3(2.0-2.8) \\
1.5(1.0-1.8)\end{array}$ \\
\hline \multicolumn{9}{|l|}{ Copper } \\
\hline $\begin{array}{r}\text { 96-h LC50 } \\
200-h \text { LC50 } \\
\text { 200-h LC10 }\end{array}$ & $\begin{array}{l}28(27-30) \\
26(24-29)^{a} \\
19(16-22)^{\mathrm{a}}\end{array}$ & $\begin{array}{r}17(15-19) \\
17(15-19) \\
9(6-11)\end{array}$ & $\begin{array}{r}18(15-22) \\
15(11-17) \\
8(3-11)\end{array}$ & $\begin{array}{c}29(>20) \\
21 \text { (all values) } \\
7(<13)\end{array}$ & $\begin{array}{l}26(24-33) \\
20(18-24) \\
15(11-17)\end{array}$ & $\begin{array}{l}19(18-21) \\
19(17-20) \\
14(12-15)\end{array}$ & $\begin{array}{l}38(35-44) \\
30(25-39) \\
17(10-21)\end{array}$ & $\begin{array}{l}26(23-35) \\
26(23-36) \\
18(12-22)\end{array}$ \\
\hline \multicolumn{9}{|l|}{ Zine } \\
\hline $\begin{array}{r}96-\mathrm{h} \text { LC50 } \\
200-\mathrm{h} \text { LC50 } \\
200 \text {-h LC10 }\end{array}$ & $\begin{array}{l}815(641-1,074) \\
555(448-692)^{\mathrm{a}} \\
256(154-336)^{\mathrm{a}}\end{array}$ & $\begin{array}{l}93(78-107) \\
93(78-107) \\
54(36-67)\end{array}$ & $\begin{array}{c}136(107-173) \\
120(102-141) \\
61(43-76)\end{array}$ & $\begin{array}{c}>651 \\
278(108-2,752) \\
84(0-168)\end{array}$ & $\begin{array}{c}>661 \\
>661 \\
364-661\end{array}$ & $\begin{array}{l}97(84-108) \\
97(84-108) \\
68(51-79)\end{array}$ & $\begin{array}{l}463(406-531) \\
395(350-448) \\
268(206-309)\end{array}$ & $\begin{array}{l}701(429-34,451) \\
364(255-599) \\
170(48-248)\end{array}$ \\
\hline
\end{tabular}

a 186-h test duration.

fied by the addition of $0.1 \mathrm{ml}$ of concentrated nitric acid per liter of stock solution.

Dissolved oxygen, $\mathrm{pH}$, total alkalinity, and total hardness were determined daily on samples from a control aquarium and at least one metal-receiving aquarium from each diluter by methods recommended by the American Public Health Association et al. (1971) and the U.S. Environmental Protection Agency (1974). These determinations were made at least once a week for each metal concentration. Water temperature was recorded continuously during all toxicity tests except those with smolts where morning and evening thermometer readings were taken.

\section{RESULTS AND DISCUSSION}

Water quality was relatively uniform throughout the series of tests; adding metal stock solutions to the aquaria caused little

TABLE 4.-Results of three-way analysis of variance of 200-h LC50 data.

\begin{tabular}{lccc}
\hline Source of variation & df & Mean square & $F^{\text {a }}$ \\
\hline Metals & 2 & 34.61 & $2,472^{*}$ \\
Species & 1 & 0.847 & $60.5^{*}$ \\
Life stages & 2 & 0.519 & $37.1^{*}$ \\
$\quad$ Linear) & 1 & 1.036 & $74.0^{*}$ \\
(Nonlinear) & 1 & 0.002 & 0.143 \\
Species $\times$ life stages & 2 & 0.249 & $17.8^{*}$ \\
Metals $\times$ life stages & 4 & 0.180 & $12.9^{*}$ \\
Error & 6 & 0.014 & \\
$\quad$ Metals $\times$ species) & 2 & 0.011 & \\
$\quad$ Metals $\times$ species & 4 & 0.015 & \\
$\quad \times$ life stage) & & & \\
\hline
\end{tabular}

${ }^{a}$ Asterisks denote significance at $P<0.05$. variation. There were no significant differences in hardness, alkalinity, or dissolved oxygen among various tests or among aquaria within a given test; the means of all test means (mg/liter $\pm \mathrm{SD}$ ) were $23 \pm 1,22 \pm 2$, and $10.2 \pm 0.3$, respectively. Median values for $\mathrm{pH}$ were generally 7.1 , with higher values (7.3 to 7.5) obtained in the steelhead parr, and chinook salmon alevin and swimup tests. In any given toxicity test the $\mathrm{pH}$ was usually constant among aquaria, although occasional deviations of $0.1 \mathrm{pH}$ unit were seen. With the possible exception of the $\mathrm{pH}$ differences, water quality probably had no effect on the life stage and species comparisons.

Mean water temperatures ranged from 11.6 to $12.8 \mathrm{C}$ (mean of means, $12.2 \pm 0.4$ SD) among the various tests, and temperatures were usually very stable $( \pm 1 \mathrm{C})$ in each test. Mean metal concentrations in control aquaria were low: cadmium, $<0.2$ $\mu \mathrm{g} /$ liter; copper, $<1 \mu \mathrm{g} /$ liter; zinc, $<3 \mu \mathrm{g} /$ liter. Mortality of control fish ranged from 0 to $3 \%$ and averaged $1 \%$. Measured metal concentrations averaged $98 \%$ of nominal (SD, $\pm 10 \%$ ).

Alevins of both species were more resistant to cadmium than were the other life stages (Table 3 ), but there appeared to be little effect of life stage on susceptibility to copper.

The series of zinc toxicity tests showed the greatest variation among life stages, although no single difference was as marked as the resistance of alevins to cadmium. As 
TABLE 5.-Relative sensitivity to zinc of eight salmonid species based on comparative acute toxicity tests which included rainbow trout (or steelhead).

\begin{tabular}{lcccc}
\hline & \multirow{2}{*}{$\begin{array}{c}\text { Relative } \\
\text { species }\end{array}$} & \multicolumn{2}{c}{ LC50 values (mg/liter) } \\
\cline { 5 - 6 } & zinc tolerance & $48-h^{\mathrm{a}}$ & $96-\mathrm{h}^{\mathrm{b}}$ & $96-\mathrm{h}^{\mathrm{c}}$ \\
\hline Atlantic salmon (Salmo salar) & 0.6 & 3.0 & & \\
Rainbow trout (Salmo gairdneri) & 1.0 & 5.0 & 0.41 & 0.14 \\
Brown trout (Salmo trutta) & 1.5 & & 0.64 & \\
Cutthroat trout (Salmo clarki) & 1.6 & & 0.67 & \\
Brook trout (Salvelinus fontinalis) & 2.3 & & 0.96 & 0.46 \\
Chinook salmon (Oncorhynchus tshawytscha) & 3.3 & & 0.75 \\
Sockeye salmon (Oncorhynchus nerka) & 5.4 & & & \\
\end{tabular}

${ }^{\text {a }}$ Herbert and Wakeford 1964.

b Nehring and Goettl 1974.

c This paper and Chapman 1978.

was the case with cadmium, the alevin was also the life stage most resistant to zinc.

In addition to the obvious tolerance of alevins to cadmium and zinc, several other patterns appeared in the data. Chinook salmon were slightly but consistently more metal tolerant than steelhead, and there was a general increase in tolerance as the fish developed through the swim-up, parr, and smolt stages. To analyze statistically the patterns within the data, the 200-h LC50 values were converted to logs and subjected to three-way analysis of variance (Table 4). For this comparison all alevin data were omitted because of the obvious tolerance of alevins to cadmium and zinc.

Each of the three primary variables (metals, species, and life stages) were significant contributors to the observed variation $(P<$ 0.05). The most important of these comparisons is that between species, which supports the observation that the chinook were more tolerant than the steelhead. The variation among metals was expected and requires no discussion. The separation of variation among life stages into linear and nonlinear components showed that the linear aspect (describing the general tendency for metal tolerance to increase with age) was significant, but that no nonlinear pattern existed. The linear effect of life stage was tested by arbitrarily treating successive stages as equally spaced age variables. The apparent increase in metal tolerance from swim-up to smolt may be a size effect as suggested by Anderson and Weber (1975), or it may reflect some other factor closely related to size or age.
There were significant differences between species and among metals with respect to effect of life stage on metal tolerance. The species $\times$ life-stage interaction appears to reflect the greater dependence of metal tolerance on life stage in chinook salmon than in steelhead. The metal $\times$ lifestage interaction is a reflection of the little variation among life stages with copper as compared to cadmium and zinc.

Based on the results of these toxicity tests, the investigator wishing to use a sensitive test fish should avoid using newly hatched alevins in metal toxicity tests. All later life stages will give generally similar results, although the smaller, younger forms appear to be more sensitive. Of course, extrapolation of these conclusions to other metals is tenuous, and application to other classes of pollutants is unwarranted.

Although no single study has compared metal toxicity among a large number of salmonid species, enough several-species comparisons of juvenile salmonids have been published to allow tentative ranking of a number of species based on acute toxicity tests with zinc (Table 5). Rainbow trout were reported to be more sensitive than brown trout or cutthroat trout, and all three of these were more sensitive than the brook trout (Nehring and Goettl 1974). Steelhead appeared to be more sensitive than chinook salmon (this paper) or sockeye salmon (Chapman 1978, this issue). Perhaps the most interesting aspect of these comparisons is the grouping of the three genera. Thus, species of Salmo may be more sensitive than brook trout (Salvelinus), while 
Pacific salmon (Oncorhynchus) seem the most tolerant. Among Salmo species, the most sensitive may be the Atlantic salmon (Herbert and Wakeford 1964). Although these comparisons may be strongly influenced by several factors including size, water temperature, and the specific strains of each species tested, Atlantic salmon and rainbow trout (or steelhead) may be the salmonids most sensitive to zinc and perhaps to other metals.

Regardless of the species or life stage used in toxicity tests, acute mortality data are seldom used directly for estimating safe levels of chemicals in natural water because chronic toxic effects usually occur at levels well below those which are acutely lethal. However, acute mortality data from metals are often utilized in estimating safe levels in fresh water; in these instances the 96-h LC50 values are multiplied by a fractional application factor. The report Water Quality Criteria 1972 (National Academy of Sciences and National Academy of Engineering 1973) recommends that safe levels of copper and zinc be estimated by multiplying the 96-h LC50 of sensitive species by the application factors 0.1 and 0.01 , respectively. Application factors, based on data from combined acute and chronic toxicity studies, are thus used to estimate safe levels from the more easily acquired acute toxicity data alone.

Acutely lethal levels of zinc to salmonids can be quite low in soft water. In addition to the 93 and $97 \mu \mathrm{g} /$ liter $96-\mathrm{h} \mathrm{LC50}$ values for steelhead and chinook salmon, other investigators report 96-h LC50 values near 100 $\mu \mathrm{g} /$ liter (Rabe and Sappington 1970; Garton 1973) and even lower LC50 values might be found in extremely soft water. Thus, predicted safe levels of zinc based on a 0.01 application factor could be at or below $1 \mu \mathrm{g} /$ liter. There are few reports on the effects of chronic zinc exposure to salmonids, and none supports the 0.01 application factor in soft water (Chapman 1978, this issue).

In the absence of chronic zinc effects below acutely lethal concentrations, estimates of minimum acute levels have considerable significance. For example, based upon the acute toxicity data of Sinley et al. (1974) the "safe" level of zinc for rainbow trout in soft water was between 36 and $71 \mu \mathrm{g} /$ liter. A similar estimate can be obtained from the 200-h LC10 values of 54,61 , and $84 \mu \mathrm{g} /$ liter for steelhead swim-ups, parr, and smolts, respectively.

The estimated safe levels for cadmium $(0.4 \mu \mathrm{g} /$ liter $)$ and copper $(0.1 \times 96-\mathrm{h}$ LC50) from Water Quality Criteria 1972 (National Academy of Sciences and National Academy of Engineering 1973) are reasonably close to the $200-\mathrm{h}$ LC10 values obtained in these tests.

While the comparative aspects of this study may not be influenced by water chemistry, the metal concentration-mortality relationships are applicable only to situations in which water chemistry is similar to that of this study. The dilution water used in these toxicity tests was typical of many $\mathrm{Pa}-$ cific coast streams with respect to dissolved inorganics (Samuelson 1976), although higher levels of metal-binding organic matter and suspended solids probably occur at least periodically in these streams.

\section{ACKNOWLEDGMENTS}

The assistance of chemists Joel McCrady and Donald Samuelson, biologist Janet Wold, and student aides Robert Claypool and Mike McCarthy is gratefully acknowledged. Donald Pierce, Oregon State University, developed the computer program used in the statistical analysis.

\section{REFERENCES}

American Public Health Association, American Water Works Association, and Water PolLUtion Control Federation. 1971. Standard methods for the examination of water and wastewater, 13th ed. Am. Public Health Assoc., New York. 874 pp.

Anderson, P. D., AND L. J. Weber. 1975. Toxic response as a quantitative function of body size. Toxicol. Appl. Pharmacol. 33:471-483.

BALON, E. K. 1975. Terminology of intervals in fish development. J. Fish. Res. Board Can. 32:16631670.

Chapman, G. A. 1978. Effects of continuous zinc exposure on sockeye salmon during adult-to-smolt freshwater residency. Trans. Am. Fish. Soc. 107:828-836.

CommitTe on Methods for Toxicity Tests With AQUatic Organisms. 1975. Methods for acute toxicity tests with fish, macroinvertebrates, and amphibians. Ecol. Res. Ser. EPA-660/3-75-009, U.S. Environ. Prot. Agency, Corvallis, Oreg. $61 \mathrm{pp}$.

Garton, R. R. 1973. Biological effects of cooling tow- 
er blowdown. Am. Inst. Chem. Eng. Symp. Ser. 69:284-292.

Herbert, D. W. M., AND A. C. WAKeFord. 1964. The susceptibility of salmonid fish to poisons under estuarine conditions. I. Zinc sulfate. Int. J. Air Water Pollut. 8:251-256.

HubBs, C. L. 1943. Terminology of early stages of fishes. Copeia 1943(4):260.

Mount, D. I., AND W. A. Brungs. 1967. A simplified dosing apparatus for fish toxicology studies. Water Res. 1:21-29.

National ACademy of Sciences and National ACADEMY of Engineering. 1973. Water quality criteria 1972. A report of the committee on water quality criteria, environmental studies board. U.S. Gov. Print. Off., Washington D.C. 594 pp.

Nehring, B. R., AND J. P. Goettl. 1974. Acute toxicity of a zinc-polluted stream to four species of salmonids. Bull. Environ. Contam. Toxicol. 12:464-469.

Norman, J. R. 1947. A history of fishes, 2nd ed. A. A. Wyn, New York. 463 pp.

Rabe, F. W., and C. W. Sappington. 1970. Biological productivity of the Coeur D'Alene rivers as related to water quality. Completion Rep. Proj. A-024-Ida. Water Resour. Res. Inst., Univ. Idaho, Moscow. $16 \mathrm{pp}$.
Samuelson, D. F. 1976. Water quality: Western Fish Toxicology Station and western Oregon rivers. Ecol. Res. Ser. EPA-600/3-76-077, U.S. Environ. Prot. Agency, Duluth, Minn. 56 pp.

Sinley, J. R., J. P. GoeTtl, AND P. H. Davies. 1974. The effects of zinc on rainbow trout (Salmo gairdneri) in hard and soft water. Bull. Environ. Contam. Toxicol. 12:193-201.

SNyDER, D. E. 1976. Terminologies for intervals in larval fish development. Pages 41-60 in John Boreman, ed. Great Lakes fish and larvae identification. U.S. Fish Wildl. Serv. FWS/OBS-76/23, Ann Arbor, Mich.

SPrague, J. B. 1969. Measurements of pollutant toxicity to fish. I. Bioassay methods for acute toxicity. Water Res. 3:793-821.

United States Envinonmental Protection AgenCY. 1974. Methods of chemical analysis of water and wastes. U.S. Environ. Prot. Agency, Off. Technol. Transfer, Washington, D.C. 298 pp.

W ARNER, R. E. 1964. Research directed toward development of test procedures for evaluating allowable limits of concentrations of toxic substances in aquatic environments. First quarterly progress report for project year 1963-64 to: Division of Water Supply and Pollution Control, U.S. Public Health Service. 